Research Paper

\title{
Oral High-Dose Ankaferd Administration Effects on Gastrointestinal System
}

\author{
Erdem Akbal ${ }^{\bowtie}$, Seyfettin Köklü², Hesna Müzeyyen Astarc1 ${ }^{3}$, Erdem Koçak ${ }^{4}$, Gökhan Karaca ${ }^{5}$, Yavuz \\ Beyazıt $^{6}$, Güler Topcu7 , Bilgehan Acar ${ }^{8}$, Dilek Ergün' ${ }^{9}$ İbrahim Celalettin Haznedaroğlu10
}

1. Department of Gastroenterology, Çanakkale Onsekiz Mart University School of Medicine, Çanakkale, Turkey;

2. Department of Gastroenterology, Hacettepe University School of Medicine, Ankara, Turkey;

3. Department of Pathology, Ankara Education and Research Hospital, Ankara, Turkey;

4. Department of Gastroenterology, Ankara Education and Research Hospital, Ankara, Turkey;

5. Department of General Surgery, Ankara Education and Research Hospital, Ankara, Turkey;

6. Department of Gastroenterology, Yuksek Ihtisas Hospital, Ankara, Turkey;

7. Department of Medical Biochemistry, Ankara Education and Research Hospital, Ankara, Turkey;

8. Department of Neurology, Sakarya University Education and Research Hospital, Sakarya, Turkey;

9. Department of Chest Diseases, Occupational Diseases Hospital, Ministry of Health, Ankara, Turkey;

10. Department of Hematology, Hacettepe University School of Medicine, Ankara, Turkey.

$\triangle$ Corresponding author: Erdem Akbal, MD. Çanakkale Onsekiz Mart University, Çanakkale, Turkey. Postal code: +901710, Email: drerdemakbal@gmail.com. Tel: +90 3125954272 Fax: + 903123633396.

(c) Ivyspring International Publisher. This is an open-access article distributed under the terms of the Creative Commons License (http://creativecommons.org/ licenses/by-nc-nd/3.0/). Reproduction is permitted for personal, noncommercial use, provided that the article is in whole, unmodified, and properly cited.

Received: 2012.07.14; Accepted: 2012.10.15; Published: 2013.03.02

\begin{abstract}
Background and aims: Ankaferd Blood Stopper (ABS) is a herbal extract obtained from five different plants. It has a therapeutic potential for the management of external hemorrhage and controlling gastrointestinal bleeding. However, ABS's effects are not unknown on gastrointestinal systems. The aim of this study was to assess the effect of short- and long-term systemic exposure and gastrointestinal safety following the oral administration of high-dose ABS in rats.

Methods: Eighteen healthy adult male rats were included into the study. The rats were divided into 4 groups: group A was fed with high dose ABS $(2 \mathrm{ml} / \mathrm{Kg})$ for one week, group B for one month, group $C$ for three months and group D's diet did not contain any ABS. On termination of the ABS treatment, the gastrointestinal system from the esophagus to the anus and the liver were surgically removed and histological investigated.

Results: During the study period, there was no mortality; signs of intoxication in any of the studied groups. No gastrointestinal tissue fibrosis, dysplasia, or metaplasia was detectable in any of the groups. The stomach had a normal morphology in all groups. However, the other gastrointestinal tract sections showed mucosal inflammation, goblet cell decrements, and intra-epithelial lymphocyte infiltration. The most common changes were mucosal inflammation in all rats in group $B$ and $C$. Frequency of inflammation was greater in groups $B$ and $C$ in comparison to group $A$ ( $P=$ $0.00 \mathrm{I})$. Loss of goblet cell and intra-epithelial lymphocyte infiltration were not significantly different between groups $A$ and $B(P=0.308$ and $P=0.189$, respectively). However, there was significantly higher intra-epithelial lymphocyte infiltration in group $C$ than in group $A(P=0.04)$. Histopathological examination of the liver showed no inflammation, fibrosis, bile duct destruction or proliferation in any of the groups. However, each groups revealed vascular dilatation and erythrocyte accumulation at the sinusoidal structures of the liver.

Conclusions: $A B S$ seems to be a safe agent and it can be used for hemorrhage originated from gastric lesions. Further work needs to be done to establish whether $A B S$ leads to be used to stop gastrointestinal bleeding.
\end{abstract}

Key words: Ankaferd blood stopper, systemic effects, oral administration, high dose. 


\section{Introduction}

Ankaferd Blood Stopper (ABS), a novel topical hemostatic agent, has been approved in Turkey for clinical hemorrhages, when the conventional control of bleeding by ligature and/or conventional hemostatic measures is ineffective (1-3). There is accumulating data of the use of Ankaferd for gastrointestinal hemorrhages. ABS has a therapeutic potential in the management of external hemorrhage and in the control of gastrointestinal bleeding associated with various lesions refractory to conventional anti-hemorrhagic measures $(1,5-21)$.

ABS is clinically effective in bleeding individuals with normal hemostatic parameters and in patients with deficient primary hemostasis and/or secondary hemostasis $(4,22-30)$. ABS-induced formation of the protein network with vital erythroid aggregation covers the entire physiological hemostatic process. Erythroid aggregation involves the spectrin, ankrin and actin receptors on the surface of red blood cells. These proteins and the required ATP bioenergy are included in the $\operatorname{ABS}(2,3,31)$. Ankaferd also upregulates GATA/FOG transcription system affecting erythroid functions (3). Urotensin II is also an essential component of Ankaferd and represents the link between injured vascular endothelium, adhesive proteins, and active erythroid cells $(31,32)$.

Although, ABS is effective control of gastrointestinal bleeding, future randomized controlled trials will elucidate whether ABS would be a safe and effective treatment option for GI bleeding. Acute mucosal toxicity, hematotoxicity, hepatotoxicity, nephrotoxicity, and biochemical toxicity were not observed during the short-term oral administration of ABS in rabbits (33). Furthermore, a case report has recently documented the safety of topical application of high-dose ABS for the control of severe GI mucosal bleeding and nasal hemorrhages (34). However, ABS exposure short and long term are not known on gastrointestinal system. The aim of this study was to assess short- and long-term systemic and gastrointestinal safety following the oral administration of high-dose ABS in rats. The objective was to analyze gastrointestinal mucosal, vascular, cellular, and biochemical effects of short-term and long-term systemic oral administration of ABS.

\section{Materials and Methods}

Twenty-three healthy adult male rats weighing 413-497 g were included in this study which was performed with the approval of the institutional review board and hospital local ethical committee. The rats were housed in stainless steel cages in the hospi- tal animal research center, in an animal room maintained at $22{ }^{\circ} \mathrm{C}$ with 12 -hour light periods. The rats were divided into 3 groups: group A was fed high dose ABS (2ml/day) for one week, group B for one month and group $C$ for three months. Group D is no-ABS treatment group and the follow-up time was one week in group D. They were fed the same amount of a laboratory pellet diet and water ad libitum and fasted for $12 \mathrm{~h}$ before the procedures. The general well-being, feeding and weight change patterns of the animals were observed during the described periods of the study. Mean body weights of the studied groups were calculated. At the end of the indicated periods, the animals were fasted overnight. Blood samples including that liver test, ürea, creatinin, lipids and electrolits were obtained just at the end of the study groups' scheduled time i.e.; at the end of week one (group A), month one (group B) and at three months (group C). The following morning, blood samples were collected from the heart. Biochemical tests including blood urea nitrogen (BUN), creatinin, albumin, cholesterol, triglyceride (TG), aspartate aminotransferase (AST), alanine aminotransferase (ALT), gamma glutamil transferase (GGT), alkaline phosphatase (ALP), lactate dehydrogenises (LDH), calcium, phosphorus and sodium were evaluated within all of the studied groups. The rats were humanely sacrificed by $\mathrm{CO}_{2}$ asphyxiation. The gastrointestinal system from the esophagus to the anus and the liver were surgically removed. The tissue samples were preserved in $10 \%$ neutral buffered formalin until studied. The stomach (proximal and distal section), duodenum, jejenum, caecum, rectum and liver of all rats were divided into two equal parts for histopathological investigations. Macroscopic scored according to as described by Morris et al (35). Four slides, five micron sections were evaluated with hematoxyline-eosin stain. Histopathological assays were performed in a blind manner by an independent pathologist.

Inflammation was defined as the presence of eosinophils, neutrophils, lymphocytes, mast cells, plasma cells and macrophages. Absence or less goblet cells than one third of epithelial cells was described as "loss of goblet cells". Intra-epithelial lymphocyte infiltration was defined as the presence of prominent intra-epithelial lymphocytes in the epithelium.

The studied parameters were expressed as the mean \pm standard error of the mean (SEM) where appropriate. The statistical significance was calculated by Fisher's exact, Kruskal-Wallis, Mann-Whitney U, Wilcoxon signed ranks. The differences were considered as statistically significant when the $P$ value was less than 0.05 . 


\section{Results}

There was no mortality, significant weight changes in any of the studied groups. Similarly, no unusual changes in the behavior or in motor activity was observed and there was, no ataxia, or signs of intoxication in any of the studied groups. In addition, there was no evidence of gastrointestinal tissue fibrosis, dysplasia, or metaplasia in any of the groups. The stomach was normal during the study period within all groups and there was no evidence of inflammation, atrophy, hypertrophia and intra-epithelial lymphocyte infiltration after the oral ABS administration. However, the duodenum, jejunum, caecum, transverse colon and rectum showed mucosal inflammation, goblet cell decrements, and intra-epithelial lymphocyte infiltration with varying severity depending on the duration of ABS administration in the studied groups.

Histopathological alterations, present after one week (group A), one month (group B) and three months (group C) of ABS administration are summarized below.

In group $\mathrm{A}$ there was no inflammation in the entire gastrointestinal system, but an $83 \%$ decrease in loss of goblet cells was found in the duodenum. There was no goblet cell loss in the jejunum and other samples. Intra-epithelial lymphocyte infiltration was found $33 \%$ in the jejunum. There was no intra-epithelial lymphocyte infiltration in other parts of the GI system in rats treated with ABS for one week.

In the group $B$ rats too there were no inflammation in the stomach and duodenum. However, inflammation was present in other parts of te GI system in all of the rats. This consisted of mixed inflammation (eosinophil, neutrophil and lymphocyte) of the jejunum $(50 \%)$ and ceacum $(66.6 \%)$, with eosinophilic and neutrophilic inflammations of the rectum in all the rats receiving one month of ABS treatment. Inflammations were observed in the lamina propria. There was also a $50 \%$ reduction in the number of Goblet cells in the duodenum. There was no goblet cell loss in the jejunum and other samples. Intra-epithelial lymphocyte infiltration was found to be $66.6 \%$ (in the duodenum $50 \%$, in the jejunum $50 \%$, and in caecum $33.4 \%$ ) of the rats in group B.

In the group $C$ rats, subjected to 3 months of oral ABS administration, inflammation, goblet cell loss and intra-epithelial lymphocyte infiltration were observed in all of the rats. Mixed inflammation included eosinophil, neutrophil and lymphocyte that were observed in the duodenum (50\%), jejunum (50\%), and caecum $(66.6 \%)$. Eosinophilic and neutrophilic inflammations of the rectum were also evident (100\%).
Inflammations were observed in the mainly lamina propria. Loss of goblet cell reductions of $66 \%$ in the duodenum and $100 \%$ in the jejunum were detectable in this group with longest exposure to ABS. Intra-epithelial lymphocyte infiltration in the duodenum, jejunum and caecum were found in all of the rats in this cohort (group C). Control group (group D) did not demonstrate any pathological changes of the liver or gastrointestinal tract.

The magnitude and frequency of inflammation was greater in groups $B$ and $C$ in comparison to group A $(P=0.001)$. Loss of goblet cell and intra-epithelial lymphocyte infiltration were not significantly different between groups $\mathrm{A}$ and $\mathrm{B}(\mathrm{P}=0.308$ and $\mathrm{P}=0.189$, respectively). However, there was significantly higher intra-epithelial lymphocyte infiltration in group $\mathrm{C}$ than in group A $(\mathrm{P}=0.04)$. The histopathological appearances and the parameters for the inflammation, loss of goblet cell and intra-epithelial lymphocyte infiltration are depicted in Table 1.

Histopathological examination of the liver showed no inflammation, fibrosis, bile duct destruction and proliferation in any of the groups. However, each groups revealed vascular dilatation and erythrocyte accumulation at the sinusoidal structures of the liver.

Table I. Pathological changes have shown in all groups.

\begin{tabular}{llll}
\hline Variables & Group A & Group B & Group C \\
\hline Initial weight (g) & $462.4 \pm 12.4$ & $445 \pm 18.9$ & $467.4 \pm 23.4$ \\
Eventual weight (g) & $460 \pm 11.2$ & $451.8 \pm 19.8$ & $457.8 \pm 26.5$ \\
İnflammation, \% & 0 & 100 & 100 \\
Stomach & & 0 & 0 \\
Duedenum & & 0 & 50 \\
Jejenum & & 50 & 50 \\
Caecum & & 66 & 66 \\
Rectum & & 100 & 100 \\
Goblet cell loss, \% & 83 & 50 & 100 \\
Stomach & 0 & 0 & 0 \\
Duedenum & 83 & 50 & 66 \\
Jejenum & 0 & 0 & 100 \\
Caecum & 0 & 0 & 0 \\
Rectum & 0 & 0 & 0 \\
İntraepithelial lymhocyt, & 33 & 66.6 & 100 \\
\% & & & \\
Stomach & 0 & 0 & 0 \\
Duedenum & 0 & 50 & 100 \\
Jejenum & 33 & 50 & 100 \\
Caecum & 0 & 33.4 & 100 \\
Rectum & 0 & 0 & 0 \\
\hline & & &
\end{tabular}


Inflammation, loss of goblet cell, intra-epithelial lymphocyte infiltration, vascular dilatation and erythrocyte accumulation in liver are shown in Figures 1-4.

The levels of plasma biochemical markers such as total protein, blood urea nitrogen (BUN), glucose,

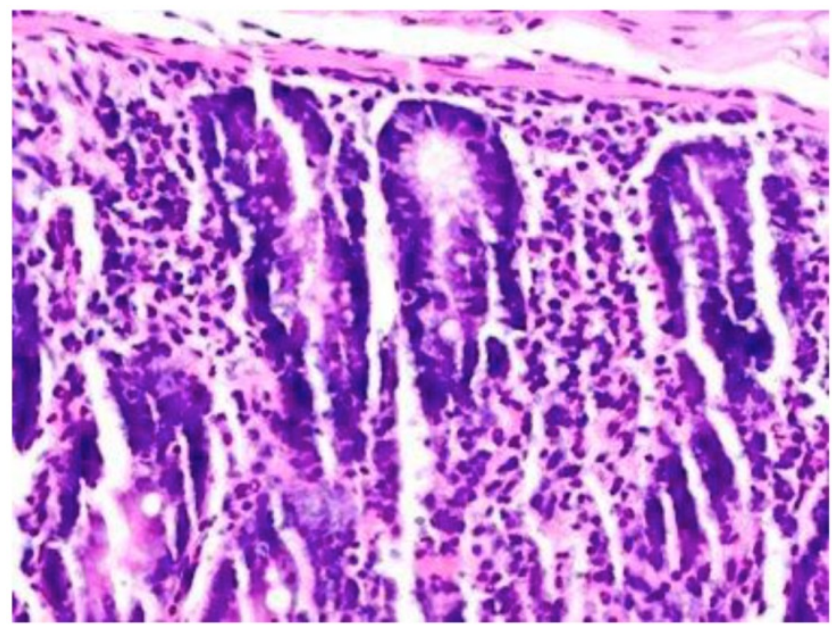

Figure I. Rectum of group C; Microscopic examination showed eosinophilic neutrophilic inflammations (hematoxylin and eosin, $\times 20)$.

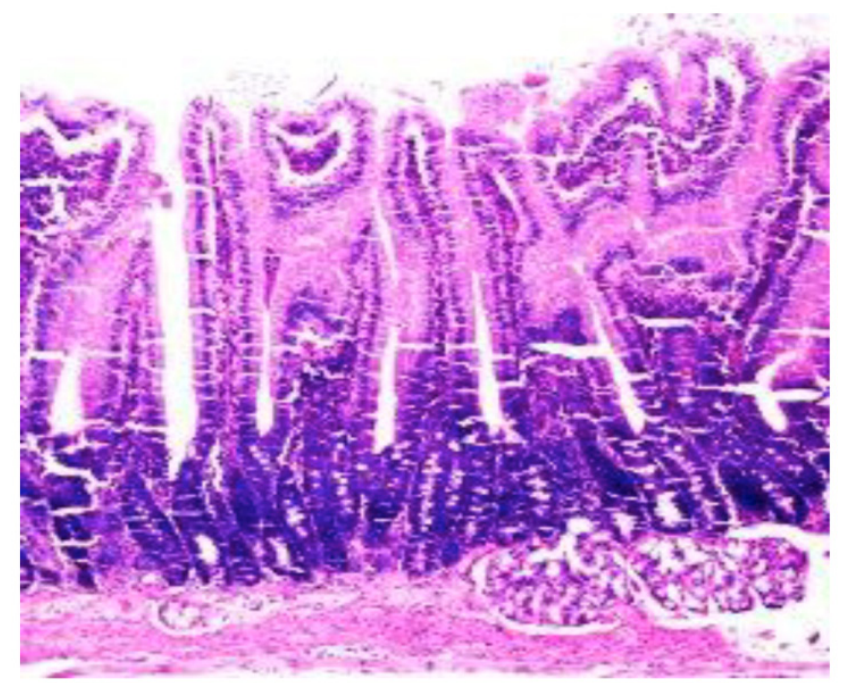

Figure 2. Jejunum of group C; Microscopic examination showed goblet cell decrements (hematoxylin and eosin, x20). bilirubin, albumin, creatinin, cholesterol, chloride, calcium, phosphorus, sodium, and potassium ions were not significantly different among the studied groups $(\mathrm{P}>0.05)$. ALT and ALP levels in group $\mathrm{B}$ and $\mathrm{C}$ were higher than in group A. Ca and phosphorus in group $\mathrm{C}$ were lower than in group A (Table 2).

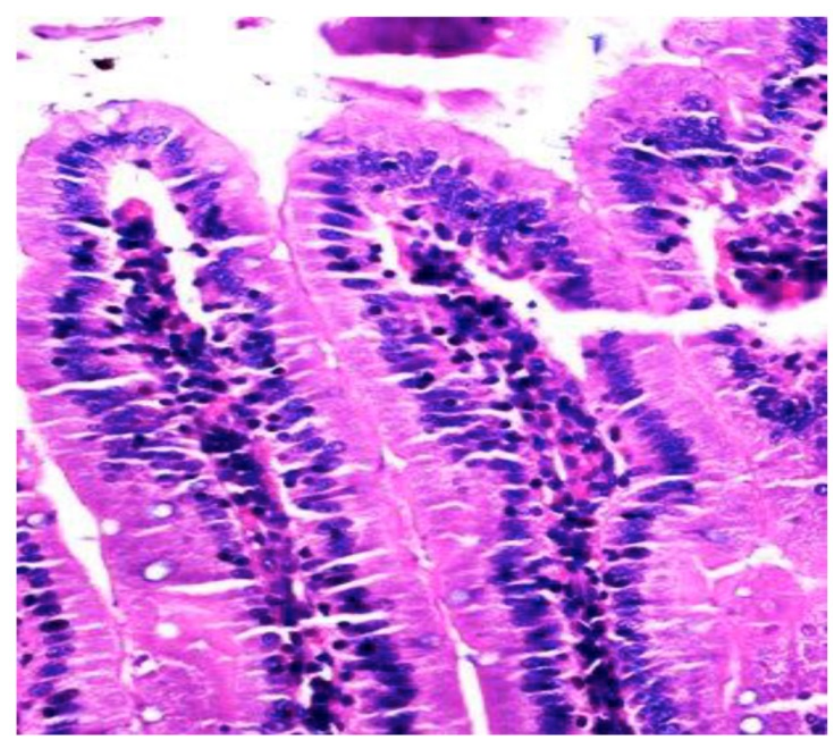

Figure 3. Duodenum of group C; Microscopic examination showed intra-epithelial lymphocyte infiltration (hematoxylin and eosin, $\times 20$ ).

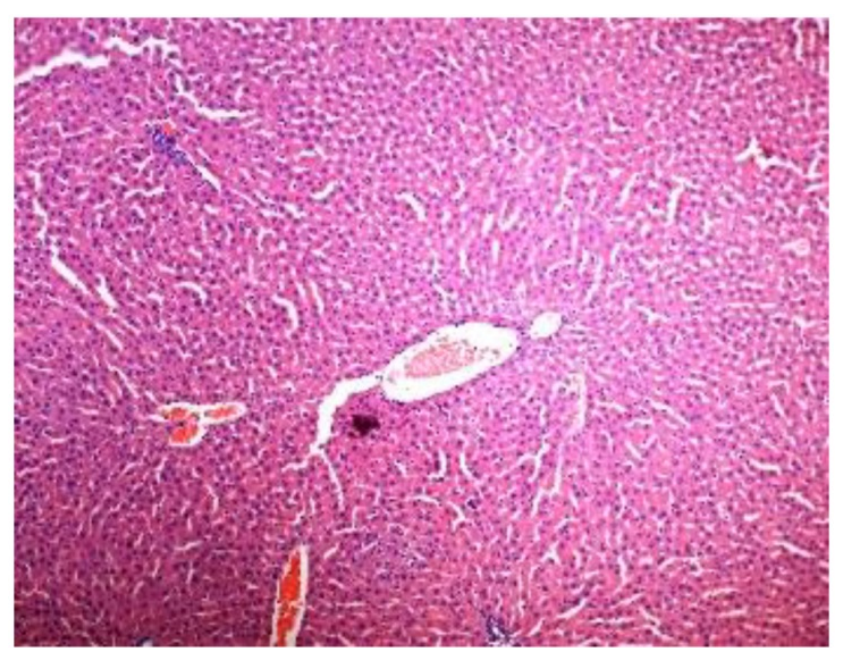

Figure 4. Microscopic examination showed vascular dilatation and erythrocyte accumulation at the sinusoidal structures of the liver in group C (hematoxylin and eosin, $\times 20$ ). 
Table 2. Biochemical measurements have shown in all groups.

\begin{tabular}{|c|c|c|c|c|}
\hline Variables & Group A & Group B & Group C & P value \\
\hline Urea, mg/dl & $37.8 \pm 6.7$ & $45.6 \pm 5.5$ & $41.0 \pm 4.4$ & 0.753 \\
\hline Creatinin, mg/dl & $0.39 \pm 0.02$ & $0.40 \pm 0.02$ & $0.38 \pm 0.02$ & 0.331 \\
\hline Albumin, g/dl & $2.51 \pm 0.05$ & $2.6 \pm 0.09$ & $2.52 \pm 0.17$ & 0.675 \\
\hline Cholesterol, mg/dl & $52.4 \pm 746$ & $56.4 \pm 13.1$ & $64.4 \pm 7.6$ & 0.465 \\
\hline Triglyceride, mg/dl & $71.2 \pm 22.0$ & $62.2 \pm 35.5$ & $43.4 \pm 12.5$ & 0.347 \\
\hline AST, IU/L & $109.8 \pm 15.6$ & $117.8 \pm 15.3$ & $110.2 \pm 9.8$ & 0.117 \\
\hline ALT, IU/L & $39.0 \pm 5.0$ & $64.6 \pm 17.2$ & $65.6 \pm 6.1$ & 0.009 \\
\hline ALP, IU/L & $79.4 \pm 15.2$ & $150.4 \pm 40.8$ & $233.2 \pm 59.2$ & 0.009 \\
\hline LDH, IU/L & $1096.2 \pm 262.3$ & $1007.2 \pm 262.8$ & $1194.6 \pm 571.7$ & 0.602 \\
\hline Calcium, mg/dl & $10.5 \pm 0.4$ & $9.7 \pm 0.1$ & $9.7 \pm 0.45$ & 0.009 \\
\hline Phosphorus, mg/dl & $6.5 \pm 0.3$ & $5.4 \pm 0.4$ & $3.8 \pm 0.5$ & 0.016 \\
\hline Sodium, $\mathrm{mEq} / \mathrm{L}$ & $138.6 \pm 1.2$ & $141.6 \pm 2.6$ & $144.0 \pm 2.1$ & 0.387 \\
\hline Potassium, mmol/L & $4.9 \pm 0.5$ & $5.1 \pm 0.6$ & $4.7 \pm 0.3$ & 0.251 \\
\hline
\end{tabular}

\section{Discussion}

Ankaferd is in clinical use in Turkey with the approval of the Turkish Ministry of Health. Although the drug is licensed for external bleedings with topical application. ABS, which has long been used as a traditional medicinal plant extract, represents an effective alternative treatment modality as a modern topical hemostatic agent for the GI bleeding, either as an adjuvant or primary agent complementing conventional methods. Although ABS is still in the early developmental stages as a drug, published observations provide encouraging preliminary safety and efficacy data for ABS in distinct states of GI bleeding as a haemostatic agent $(1,4-21)$. These observations include, the reported efficacy of ABS as an adjunctive drug in difficult upper GI bleedings with low platelet count, defective hemostasis, tumoral gastrointestinal bleeding, variceal bleeding, and severe radiation colitis. But there is still lack of evidence that supports the use of ABS use. In this study found that stomach in all ABS groups were normal. Stomach were no showed any histological abnormalities included that inflammation, fibrosis and loss of goblet cell For that reason it is important to detect the side effects of Ankaferd to stomach. Our preliminary study to demonstrate the safety of Ankaferd to stomach mucosa even taken by orally. However, we detected deceases in the intestinal goblet cells associated with intra-epithelial lymphocyte infiltration and mild inflammation during the long-term oral systemic ABS administration.

Goblet cells reside throughout the length of the small and large intestine and are responsible for the production and maintenance of mucus blanket by synthesizing and secreting high-molecular-weight glycoproteins known as mucins (12). The goblet cell depletion seen during the ABS administration may reflect the death or functional alteration of goblet cells. The biological consequences of the functional modulation of goblet cells are not currently clear. We could hypothesize that goblet cell function during ABS administration may be subject to modulation by the drug and components of the host's immune system. In particular the histological detection of increased intra-epithelial lymphocyte infiltration could suggest the involvement of the cellular immune system. Previous studies have detected decreased expression of Goblet cell-specific genes (10). It seems paradoxical that the host immune system reduces intestinal expression of goblet cell-derived proteins, their protective roles (13). Assessment of the beneficial or harmful effects of the impact of immune mediated loss of intestinal goblet cells, which appear to be associated with oral $\mathrm{ABS}$ administration, require further investigations.

ABS has positive effects on early bone healing together with decreasing inflammation and necrosis as well as increasing new bone formation (14). Furthermore, a recent study has demonstrated that adding ABS to the pancreatic secretions produces protein aggregates, resulting in a solid layer over the pancreatic fluid like a frozen gel, with important in vitro biochemical alterations $(10,36)$. The interrelationships between ABS-induced immune system-driven loss of intestinal goblet cells, anti-infective actions of ABS, and its association with hemostatic activities remain to be elucidated.

Given the current interest in the study and development of ABS for clinical application, the novel observations made in the present study, warrant further analysis of the pleiotropic effects of ABS as a 
hemostatic agent. One area of focus for future studies could be the in vivo effects of ABS on gastrointestinal tissues in both normal and pre-clinical disease models, and in particular the effect of ABS on the expression on secretory and membrane protein. We think that this study will open new avenues for the clinicians who want to use Ankaferd for gastrointestinal bleeding and long term in gastrointestinal disorders.

\section{Competing Interests}

The authors have declared that no competing interest exists.

\section{References}

1. Beyazit Y, Kurt M, Kekilli M, et al. Evaluation of hemostatic effects of Ankaferd as an alternative medicine. Altern Med Rev 2010;15:329-336.

2. Haznedaroglu BZ, Haznedaroglu IC, Walker SL, et al. Ultrastructural and morphological analyses of the in vitro and in vivo hemostatic effects of Ankaferd Blood Stopper. Clin Appl Thromb Hemost 2010;16:446-453.

3. Haznedaroglu IC. Molecular Basis of the Pleiotropic Effects of Ankaferd Blood Stopper. IUBMB Life 2009;61:290-290.

4. Yarali N, Oruc M, Bay A, et al . A new hemostatic agent--Ankaferd blood stopper: management of gastrointestinal bleeding in an infant and other experiences in children. Pediatr Hematol Oncol 2010;27:592-596.

5. Ozaslan E, Purnak T, Ozyigit G, et al. No prolonged effect of Ankaferd Blood Stopper on chronic radiation proctitis. Endoscopy 2010;42: E271-272.

6. Ozaslan E, Purnak T, Yildiz A, et al. The effect of Ankaferd blood stopper on severe radiation colitis. Endoscopy; 2009; 41: 321-322.

7. Ozaslan E, Purnak T, Yildiz A, et al. Bleeding due to slippage of elastic band during variceal ligation: successful use of Ankaferd blood stopper. Indian J Gastroenterol 2010; 29: 166-168.

8. Ozaslan E, Purnak T, Yildiz A, et al. The effect of a new hemostatic agent for difficult cases of non-variceal gastrointestinal bleeding: Ankaferd blood stopper. Hepatogastroenterology 2010; 57: 191-194.

9. Ozaslan E, Purnak T, Yildiz A, et al. A new practical alternative for tumoural gastrointestinal bleeding: Ankaferd blood stopper. Dig Liver Dis 2010; 42: 594-595

10. Tuncer I, Doganay L, Ozturk O. Instant control of fundal variceal bleeding with a folkloric medicinal plant extract: Ankaferd Blood Stopper. Gastrointest Endosc $2010 ; 71$ : 873-875.

11. Turhan N, Kurt M, Shorbagi A, et al. Topical Ankaferd Blood Stopper administration to bleeding gastrointestinal carcinomas decreases tumor vascularization. Am J Gastroenterol 2009; 104: 2874-2877.

12. Specian RD, Oliver MG. Functional Biology of Intestinal Goblet Cells. American Journal of Physiology 1991; 260: 183-193.

13. Bergstrom KS, Guttman JA, Rumi M, et al. Modulation of intestinal goblet cell function during infection by an attaching and effacing bacterial pathogen. Infect Immun 2008; 76: 796-811.

14. Isler SC, Demircan S, Cakarer S, et al. Effects of folk medicinal plant extract Ankaferd Blood Stopper (R) on early bone healing. Journal of Applied Oral Science 2010; 18: 409-414.

15. Akkoc N, Akcelik M, Haznedaroglu IC, et al. In Vitro Anti-Bacterial Activities of Ankaferd Medicinal Plant Extract. Turkiye Klinikleri Tip Bilimleri Dergisi 2009;29:410-415

16. Tasdelen Fisgin N, Tanriverdi Cayci Y, Coban AY, et al. Antimicrobial activity of plant extract Ankaferd Blood Stopper. Fitoterapia 2009;80:48-50.

17. Sarıbafl Z, fiener B, Haznedaroglu IC, Hasçelik G, et al. Antimicrobial activity of Ankaferd Blood StopperA (R) against nosocomial bacterial pathogens. Central European Journal of Medicine 2010;5:198-202.

18. Akgül T, Huri E, Ayyıldız A, et al. Haemostatic and Histopathological Effects of Ankaferd Blood Stopper, on Penile Cavernosal Tissue in Rats. International Journal of Hematology and Oncology 2009;19:159-165.

19. Shorbagi A, Sivri B. Successful management of a difficult case of radiation proctopathy with Ankaferd BloodStopper: a novel indication (with video). Gastrointest Endosc 2010;72:666-667.

20. Turhan N, Bilgili H, Captug O, et al. Evaluation of A Haemostatic Agent in Rabbits. African Journal of Traditional Complementary and Alternative Medicines 2011; 8: 61-65.
21. Atzori L, Lucattelli M, Scotton CJ, et al. Absence of Proteinase-Activated Receptor-1 Signaling in Mice Confers Protection from fMLP-Induced Goblet Cell Metaplasia. Am. J. Respir. Cell Mol. Biol. 2009; 41: 680-687.

22. Al B, Yildirim C, Cavdar M, Zengin S, et al. Effectiveness of Ankaferd blood stopper in the topical control of active bleeding due to cutaneous-subcutaneous incisions. Saudi Med J 2009;30:1520-1525.

23. Arslan S, Haznedaroglu IC, Oz B, et al. Endobronchial application of Ankaferd blood stopper to control profuse lung bleeding leading to hypoxemia and hemodynamic instability. Respiratory Medicine 2008; doi:10.1016/j.rmedc.2008.10.016

24. Balcik OS, Koroglu M, Cipil H, et al. A Placebo-Controlled, Randomized, Double-Blinded, Cross-Over Phase I Clinical Study to Demonstrate Safety of Ankaferd Blood Stopper Topical Usage In Healthy Volunteers. Int J Lab Hem 2010;32:126-127.

25. Kurt M, Akdogan M, Onal IK, et al. Kurt M, Akdogan M, Onal IK, et al. Endoscopic topical application of Ankaferd Blood Stopper for neoplastic gastrointestinal bleeding: A retrospective analysis. Dig Liver Dis 2010;42:196-199.

26. Kurt M, Onal I, Akdogan M, et al. Ankaferd Blood Stopper for controlling gastrointestinal bleeding due to distinct benign lesions refractory to conventional antihemorrhagic measures. Can J Gastroenterol 2010;24:380-384.

27. Meric Teker A, Korkut AY, Kahya V, et al. Prospective, randomized, controlled clinical trial of Ankaferd Blood Stopper in patients with acute anterior epistaxis. Eur Arch Otorhinolaryngol 2010;267:1377-1381.

28. Teker AM, Korkut AY, Gedikli O, et al. Prospective, controlled clinical trial of Ankaferd Blood Stopper in children undergoing tonsillectomy. Int J Pediatr Otorhinolaryngol 2009;73:1742-1745.

29. Turhan N, Kurt M, Shorbagi A, et al. Topical Ankaferd Blood Stopper administration to bleeding gastrointestinal carcinomas decreases tumor vascularization. Am J Gastroenterol 2009;104:2874-2877.

30. Zulfikar OB, Emiroglu HH, Kebudi R. Nasogastric application of topical Ankaferd Blood Stopper for bleeding from primary esophageal adenocarcinoma in a child with disseminated intravascular coagulation. Dig Liver Dis. 2011;43:247-248.

31. Demiralp DO, Haznedaroglu IC, Akar N. Functional proteomic analysis of Ankaferd (R) Blood Stopper. Turkish Journal of Hematology 2010;27:70-77.

32. Yilmaz E, Gulec S, Haznedaroglu IC, et al. The effects of Ankaferd ${ }^{\circledR}$ Blood Stopper on transcription factors in HUVEC and erythrocyte protein profile. Turk J Hematol 2011; in press.

33. Bilgili H, Captug O, Kosar A, et al. Oral systemic administration of Ankaferd blood stopper has no short-term toxicity in an in vivo rabbit experimental model. Clin Appl Thromb Hemost. 2010;16:533-536.

34. Kurt M, Oztas E. Kuran S, et al. Tandem oral, rectal, and nasal administrations of Ankaferd Blood Stopper to control profuse bleeding leading to hemodynamic instability. Am J Emerg Med 2009;27:631-632.

35. Morris GP, Beck PL, Herridge MS, Depew WT, Szewczuk MR, Wallace JL. Hapten-induced model of chronic inflammation and ulceration in the rat colon. Gastroenterology 1989;96: 795-803.

36. Karaman K, Celep B, Bostanci EB, et al. Effects of Ankaferd Blood Stopper on pancreatic fluid: An in vitro study. ANZ J Surg 2010;80:946-947. 